\title{
Vascular Endothelial Growth Factor Stimulates Rat Cholangiocyte Proliferation Via an Autocrine Mechanism
}

\author{
EUGENIO GAUDIO,* BARBARA BARBARO,*,^,§ DOMENICO ALVARO,§ SHANNON GLASER," \\ HEATHER FRANCIS," YOSHIYUKI UENO, " CYNTHIA J. MEININGER, ${ }^{\dagger}$ ANTONIO FRANCHITTO,* \\ PAOLO ONORI, ${ }^{*}$ MARCO MARZIONI, $\$ \$$ SILVIA TAFFETANI, " GIAMMARCO FAVA, ${ }^{\ddagger}$ GEORGE STOICA, ${ }^{\ddagger}$ \\ JULIE VENTER, ${ }^{\ddagger}$ RAMONA REICHENBACH,** SHARON DE MORROW," RYUN SUMMERS, ${ }^{\ddagger}$ and \\ GIANFRANCO ALPINI ${ }^{\ddagger} * *$, , \\ *Divisions of Anatomy and \$Gastroenterol Polo Pontino, University “La Sapienza," Rome, Italy; ”Department of System Biology and \\ Translational Medicine, "Division of Research and Education, **Central Texas Veterans Health Care System, and ${ }^{\star \dagger}$ Department of Medicine, \\ Scott \& White Hospital and the Texas A\&M University System Health Science Center, College of Medicine, Temple, Texas; "Division of \\ Gastroenterology, Tohoku University Hospital, Aobaku, Sendai, Japan; "Department of Experimental Medicine, University of L'Aquila, L'Aquila, \\ Italy; and ${ }^{\S}$ Department of Gastroenterology, Università Politecnica delle Marche, Ancona, Italy
}

Background \& Aims: Vascular endothelial growth factor (VEGF) is secreted by several epithelia and modulates cellular functions by autocrine and paracrine mechanisms. The role of VEGF in cholangiocyte pathophysiology is unknown. We evaluated the role of VEGF in the regulation of cholangiocyte proliferation in rats that underwent bile duct ligation. Methods: The expression of VEGF-A and VEGF-C and their receptors in cholangiocytes from normal and BDL rats was evaluated. Normal or BDL rats were treated with recombinant-VEGF-A or recombinant-VEGF-C or anti-VEGF antibodies, and proliferation of cholangiocytes was evaluated in situ by morphometry and in vitro by proliferating cell nuclear antigen immunoblots and MTS assay. In vitro, normal rat cholangiocyte cultures were stimulated with r-VEGF-A or r-VEGF-C and proliferation and signal transduction were evaluated. Results: We found that (1) cholangiocytes express messenger RNA and protein for VEGF-A, VEGF-C, VEGF receptor 2 (VEGFR-2), and VEGF receptor 3 (VEGFR-3) and secrete VEGF; (2) secretion of VEGF and expression of VEGFR-2 and VEGFR-3 increases in BDL cholangiocytes; (3) blocking VEGF in vivo by anti-VEGF-A or anti-VEGF-C antibodies decreases cholangiocyte proliferation; (4) the in vivo administration of r-VEGF-A or r-VEGF-C induces cholangiocyte proliferation in normal rats; and (5) in vitro, VEGF-A increases normal rat cholangiocyte culture proliferation by activation of inositol 1,4,5-triphosphate/ $\mathrm{Ca}^{2+} /$ protein kinase $\mathrm{C} \alpha$ and phosphorylation of Src/ERK1/2. Conclusions: Cholangiocytes secrete VEGF and express VEGFR-2 and VEGFR-3, all of which are amplified in BDL cholangiocytes. VEGF induces cholangiocyte proliferation by activation of inositol 1,4,5-triphosphate/[ $\left.\mathrm{Ca}^{2+}\right]_{/} /$protein kinase $C \alpha$ and phosphorylation of Src/ERK1/2. VEGF mediates the adaptive proliferative response of cholangiocytes to cholestasis.
T ascular endothelial growth factor (VEGF) is a family of related growth factors that includes VEGF-A, -B, $-\mathrm{C},-\mathrm{D}$, and $-\mathrm{E}$ and placenta growth factor. ${ }^{1-4}$ VEGF is a mitogen for vascular endothelial cells and regulates vascular pathophysiology, including vasodilatation, vascular permeability, migration, and survival of endothelial cells. $^{2-4}$ The expression of VEGF and its receptors is not restricted to vascular endothelial cells because their expression has been detected in vascular smooth muscle cells, osteoblasts, regenerating myotubes, and hematopoietic stem cells. ${ }^{2-5}$ VEGF is secreted by several epithelia, where it modulates cell growth by autocrine and paracrine mechanisms. ${ }^{6,7}$ Two distinct tyrosine kinase receptors have been identified for VEGF (VEGFR), VEGFR-1 (Flt-1) and VEGFR-2 (Flk-1), which share $44 \%$ amino acid homology. ${ }^{2-4}$ A third receptor, VEGFR-3 (Flt-4), has been identified. ${ }^{2-4}$ While VEGF-A interacts with VEGFR-2, VEGF-C interacts with VEGFR-3.2-4

The function of the intrahepatic biliary tree is linked with its vascular supply sustained by the peribiliary arterial plexus (PBP). ${ }^{8}$ Alterations of intrahepatic bile duct mass are associated with changes of the PBP architecture. ${ }^{8,9}$ Following bile duct ligation (BDL), the PBP

\footnotetext{
Abbreviations used in this paper: $\mathrm{BDL}$, bile duct ligation; bp, base pairs; BSA, bovine serum albumin; GAPDH, glyceraldehyde-3-phosphate dehydrogenase; GGT, $\gamma$-glutamyltransferase; $I P_{3}$, inositol 1,4,5triphosphate; NRICC, normal rat intrahepatic cholangiocyte culture; PBP, peribiliary arterial plexus; PCNA, proliferating cell nuclear antigen; PKC, protein kinase C; r-VEGF, recombinant vascular endothelial growth factor; VEGF, vascular endothelial growth factor; VEGFR, vascular endothelial growth factor receptor.

(c) 2006 by the American Gastroenterological Association Institue 0016-5085/06/ $\$ 32.00$ doi:10.1053/j.gastro.2005.12.034
} 
undergoes marked proliferation, thus supporting the increased nutritional and functional demands from the proliferated bile ducts. ${ }^{8}$ However, the proliferation of the PBP occurs only after the hyperplasia of the intrahepatic biliary epithelium. ${ }^{8}$ This finding suggests a cross-talk mechanism between cholangiocytes and endothelial cells that mediates the adaptive changes of these cells during liver damage. ${ }^{10}$

The aims of this study were to (1) evaluate the expression of VEGF-A and VEGF-C and their receptors in normal and proliferating cholangiocytes after BDL and (2) determine the role and transduction mechanisms by which VEGF-A and VEGF-C regulate cholangiocyte proliferation.

\section{Materials and Methods}

\section{Materials}

Reagents were purchased from Sigma Chemical Co (St Louis, MO) unless otherwise indicated. The antibodies against proliferating cell nuclear antigen (PCNA), VEGF-A and VEGF-C, and the VEGF receptor subtypes VEGFR-1, VEGFR-2, and VEGFR-3 were purchased from Santa Cruz Biotechnology, Inc. (Santa Cruz, CA). The recombinant mouse VEGFs (r-VEGF-A and r-VEGF-C) were purchased from Leinco Technologies, Inc. (St Louis, MO). The inositol 1,4,5trisphosphate $\left(\mathrm{IP}_{3}\right)\left[{ }^{3} \mathrm{H}\right]$ kit, for the determination of intracellular $\mathrm{IP}_{3}$ levels, was purchased from Amersham (Piscataway, $\mathrm{NJ})$. The rabbit polyclonal antibody recognizing von Willebrand factor (Factor VIII-related antigen) was purchased from Chemicon International, Inc. (Temecula, CA). The antibodies for rabbit anti-phospho-Src (Tyr 139), mouse anti-total Src, mouse anti-p-JNK (which detects JNK1, JNK2, and JNK3 phosphorylated at Thr-183 and Tyr-185 of JNK1), rabbit anti-total JNK (which reacts with total JNK1, JNK2 p 54 , and JNK3), mouse anti-p-p38 (which detects Tyr-182 phosphorylated mitogen-activated protein kinase $\mathrm{p} 38, \mathrm{Mxi2}$, and p38 $\beta$ ), mouse anti-p38 (which detects total p38 and p38ß), rabbit anti-ERK1 (which detects $\mathrm{p} 44$ and $\mathrm{p} 42$ ), rabbit antiERK2 (which detects p44 and p42), and goat anti-pERK (which detects phosphorylated p44 and p42) were purchased from Santa Cruz Biotechnology, Inc.

\section{Animal Models}

Male Fischer 344 rats (150-175 g) were purchased from Charles River (Wilmington, MA). The animals were kept in a temperature-controlled environment $\left(22^{\circ} \mathrm{C}\right)$ with a 12 hour light/dark cycle and fed ad libitum rat chow. The studies were performed in (1) normal rats and 1-week BDL rats; (2) rats that (immediately after BDL) were treated with a daily intraperitoneal injection of nonimmune serum, anti-VEGF-A or anti-VEGF-C antibody, mouse anti-human VEGF antibody (which immunoneutralizes VEGF; Calbiochem Biochemicals, San Diego, CA), ${ }^{11,12}$ or combined anti-VEGF A $+\mathrm{C}$ antibody (10 ng/day) for 1 week; and (3) normal rats treated by intra- peritoneally implanted Alzet osmotic minipumps (Durect Corp., Cupertino, CA) with $0.2 \%$ bovine serum albumin (BSA), r-VEGF-A, or r-VEGF-C $\left(2.5 \mathrm{nmol} \cdot \mathrm{kg}^{-1} \cdot \mathrm{h}^{-1}\right)$ with $0.2 \%$ BSA for 1 week. BDL was performed as described. ${ }^{10}$ The dose (nanomolar range) of anti-VEGF-A, anti-VEGF-C, $r$ VEGF-A, or r-VEGF-C administered to rats was chosen according to the concentration (nanomolar range) of VEGF found in the serum of our animals (see following text). This dose was similar to that found in rats and humans. ${ }^{13,14}$ Before each procedure, animals were anesthetized with sodium pentobarbital $(50 \mathrm{mg} / \mathrm{kg}$ body wt intraperitoneally). Study protocols were performed in compliance with institution guidelines.

\section{Normal Rat Intrahepatic Cholangiocyte Cultures and Purified Cholangiocytes and Hepatocytes}

Normal rat intrahepatic cholangiocyte cultures (NRICCs) were obtained as described by us. ${ }^{15}$ Hepatocytes were isolated by collagenase perfusion. Cholangiocytes $(97 \%-$ $100 \%$ pure by $\gamma$-glutamyltransferase [GGT] histochemistry $)^{16}$ were obtained by immunoaffinity separation. ${ }^{17-20}$ Cell number and viability ( $>97 \%$ ) were assessed by trypan blue exclusion.

\section{Expression of VEGF Receptors and VEGF-A and VEGF-C}

The expression of VEGF receptors (VEGFR-1, VEGFR-2, and VEGFR-3) and VEGF-A and VEGF-C was evaluated by (1) immunohistochemistry (VEGFR-1, VEGFR-2, VEGFR-3, VEGF-A, and VEGF-C) or immunofluorescence (VEGFR-1) in paraffin-embedded liver sections (n $=6$ per group, $5 \mu \mathrm{m}$ thick), (2) reverse-transcription polymerase chain reaction (AmpliTaq DNA polymerase; PE Applied Biosystems, Foster City, CA) in total RNA ( $1 \mu \mathrm{g})$ from cholangiocytes by the GenElute (Sigma-Aldrich, St. Louis, MO) total mammalian RNA kit, and (3) immunoblots of protein $(10 \mu \mathrm{g})$ from whole cholangiocyte lysates and NRICCs.

Immunohistochemistry for VEGFR-1, VEGFR-2, VEGFR-3, VEGF-A, and VEGF-C was performed as follows. Following incubation with the selected antibody, liver sections were rinsed with $1 \times$ phosphate-buffered saline, incubated with a biotinylated secondary antibody (DAKO LSAB2, Milan, Italy), with DAKO ABC (Dako LSAB2), and developed with 3,3'-diaminobenzidine. Sections were analyzed in a coded fashion using an Olympus BX-51 light microscope (Tokyo, Japan) with a Videocam (Spot Insight; Diagnostic Instrument, Inc, Sterling Heights, MI) and processed with an Image Analysis System (IAS - Delta Sistemi, Rome, Italy). For immunofluorescence for VEGFR-1, following blocking of nonspecific binding of immunoglobulin G, BDL liver sections were incubated with a polyclonal antibody against VEGFR-1. Following washes, the specimens were incubated with a biotin-conjugated secondary antibody. Sections were incubated in a dark chamber with streptavidin CY3 (Jackson Europe Ltd; Soham, Cambridgeshire, UK) for 15 minutes. After washing, the sections were mounted with Vectorshield mounting medium with 4',6-diamidino-2-phenylindole (Vector Laboratories, Bur- 
lingame, CA) and examined using a Reichert Jung Diastar fluorescence microscope (Hicksville, NY).

Specific oligonucleotide primers for VEGFR-2 were based on the rat VEGFR-2 sequence ${ }^{21}$ (sense 5'- GTGATTGCCATGTTCTTCTGGC-3' and antisense 5'-TCAGACATGAGAGCTCGATGCT-3', 337 base pairs [bp]). Specific oligonucleotide primers for rat VEGFR-3 were designed based on the human VEGFR-3 sequence ${ }^{22}$ (sense 5' - CACTCCCGCCATACGCCACATCAT- 3 ' and antisense 5'-CTGCTCTCTATCTGCTCAAACTCC-3', 450 bp). Specific oligonucleotide primers for VEGF-A were based on the rat VEGF-A sequence ${ }^{23}$ (sense $5^{\prime}$ ACCTCCACCATGCCAAGT- $3{ }^{\prime}$ and antisense 5'-TAGTTCCCGAAACCCTGA-3', expected fragments bands: 434 bp [VEGF 120-amino acid isoform], 565 bp [VEGF 164-amino acid isoform], and 687 bp [VEGF 188-amino acid isoform]). Specific oligonucleotide primers for VEGF-C were based on the rat VEGF-C sequence ${ }^{24}$ (sense 5'-CTGTGGACCCAACAAGGAGT-3' and antisense 5'-CAGGCACATTTTCCAGGATT-3', $243 \mathrm{bp}$ ). The equality of the RNA used was assessed by reversetranscription polymerase chain reaction for the housekeeping gene glyceraldehyde-3-phosphate dehydrogenase (GAPDH) (sense 5'GTGACTTCAACAGCAACTCCCATTC-3' and antisense 5'GTTATGGGGTCTGGGATGGAATTGTG-3', 294 bp); primers were based on the rat GAPDH sequence. ${ }^{25}$ Standard reversetranscription polymerase chain reaction conditions were used with $1 \mu \mathrm{g}$ of total messenger RNA (mRNA) (35 step cycles: 30 seconds at $94^{\circ} \mathrm{C}, 30$ seconds at $52^{\circ} \mathrm{C}$, and 45 seconds at $72^{\circ} \mathrm{C}$ ). The polymerase chain reaction samples for VEGFR-2, VEGFR-3, VEGF-A (434 bp [VEGF 120-amino acid isoform] and 565 bp [VEGF 164-amino acid isoform]), and VEGF-C were run on agarose gels, and the bands were excised and removed from the gel with the Qiaquick Gel Extraction Kit (Qiagen, Valencia, CA). We were not able to sequence the VEGF-A isoform (687 bp [VEGF 188-amino acid isoform]) due to the low yield of this message after gel elution. The purified fragments were sequenced by Davis Sequencing (Davis, CA).

The expression of VEGFR-2, VEGFR-3, VEGF-A, and VEGF-C was evaluated by immunoblots of protein $(10 \mu \mathrm{g})$ from whole cholangiocyte lysates from normal and BDL rats. The intensity of the enhanced chemiluminescence-visualized bands was determined by scanning video densitometry using the ChemiImager 4000 Low Light Imaging System (Alpha Innotech Corp, San Leandro, CA).

\section{Measurement of Hepatocyte and Cholangiocyte VEGF Secretion and VEGF Serum Concentration}

To determine VEGF secretion, primary cultures of hepatocytes or cholangiocytes $\left(1 \times 10^{6}\right)$ were incubated at $37^{\circ} \mathrm{C}$ for 0 or 6 hours. Then cells were centrifuged and the supernatant $(100 \mu \mathrm{L})$ was transferred to a tube and analyzed for VEGF concentration by enzyme-linked immunosorbent assay using commercially available kits (Peninsula Laboratories Inc, San Carlos, CA). Hepatocyte or cholangiocyte VEGF secretion (nanogram per $1 \times 10^{6}$ cells) was calculated as the difference between the amount of VEGF detected at 6 hours and the amount detected at time 0 . We measured by enzymelinked immunosorbent assay kits (Peninsula Laboratories Inc) the changes in VEGF concentration in serum from normal and BDL rats.

\section{Effect of Administration of Anti-VEGF-A or Anti-VEGF-C Antibody on Body Weight, Inflammation, Necrosis, Lobular Damage, Apoptosis, and Cholangiocyte Growth}

To evaluate the effects of VEGF neutralization on cholangiocyte proliferation, we tested 2 antibodies (antiVEGF-A and anti-VEGF-C) that bind to the functional domains of VEGF-A and VEGF-C, respectively (Santa Cruz data sheets and http://www.ebi.uniprot.org) and an additional antibody (anti-VEGF) reported to block all 3 isoforms of VEGF-A identified in cholangiocytes. ${ }^{11,12}$ To demonstrate that the mouse anti-human VEGF antibody ${ }^{11,12}$ interacts with rat bile ducts, we have performed immunohistochemistry with this antibody in normal and BDL liver sections.

We evaluated the degree of portal inflammation, necrosis, and lobular morphology (disarrangement of hepatocytes). Ten randomly selected portal areas and surrounding lobular areas were evaluated using light microscopy of H\&E-stained sections ( $5 \mu \mathrm{m}$ thick, 3 sections evaluated per each group of animals, $n=2$ ). For quantification of damage, the following categories were applied: 0 , null; 1 , limited to portal area; 2, intermediate; and 3, panlobular. Liver sections were examined in a coded fashion by light microscopy with an Olympus BX-40 (Tokyo, Japan) microscope equipped with a camera. Apoptosis was determined by terminal deoxynucleotidyl transferase-mediated deoxyuridine triphosphate nick-end labeling analysis $^{26}$ (Wako Chemicals, Tokyo, Japan) in sections evaluated in a coded fashion with a microscope (U-PMTVC; Olympus Optical Co, Tokyo, Japan); 200 cells per slide were counted in 10 nonoverlapping fields.

Cholangiocyte proliferation was evaluated by measurement of (1) the number of PCNA- and CK-19-positive cholangiocytes and GGT-positive ducts in liver sections ( $5 \mu \mathrm{m}$ thick, 3 slides analyzed per animal) $)^{16,20,27}$ and (2) PCNA protein expression in protein $(10 \mu \mathrm{g})$ from whole cholangiocyte lysates. Proliferation of vascular endothelial cells was evaluated by immunohistochemistry for PCNA and Factor VIII-related antigen (a marker of endothelial cells) ${ }^{28}$ in liver sections $(5 \mu \mathrm{m}$, 3 slides analyzed per animal) from normal, 1-week BDL, and 2-week BDL rats. Sections were counterstained with hematoxylin and examined with a microscope (Olympus BX 40; Olympus Optical Co). For PCNA, CK-19, VEGFR-1, VEGFR-2, and VEGFR-3 staining, more than 100 cholangiocytes were counted in a random, blinded fashion in 3 different fields for each group of animals. For GGT staining, more than 20 bile ducts were counted in 7 different fields for each group of animals.

Cholangiocyte proliferation was also evaluated by immunoblots for PCNA in protein $(10 \mu \mathrm{g})$ from whole cholangiocyte lysates. The intensity of the enhanced chemiluminescence- 
visualized bands was determined by scanning video densitometry using the ChemiImager 4000 Low Light Imaging System.

\section{Effect of Administration of r-VEGF-A or r- VEGF-C on Normal Cholangiocyte Proliferation}

To show that VEGF stimulates cholangiocyte proliferation, normal rats were treated with $0.2 \%$ BSA, r-VEGF-A, or r-VEGF-C for 1 week. We measured cholangiocyte proliferation by evaluating the number of PCNA- and CK-19positive cholangiocytes and GGT-positive ducts in liver sections ( 3 slides analyzed per animal, $5 \mu \mathrm{m}$ thick).

\section{r-VEGF-A and r-VEGF-C Stimulates NRICC Proliferation}

In NRICCs, we evaluated the effect of r-VEGF-A and r-VEGF-C (100 nmol/L) on intracellular $\mathrm{IP}_{3}$ and $\mathrm{Ca}^{2+}$ levels, ${ }^{29}$ 2 second messengers activated by VEGF. ${ }^{30,31}$ For $\mathrm{IP}_{3}$ measurements, NRICCs $\left(5 \times 10^{6}\right)$ were incubated for 1 hour at $37^{\circ} \mathrm{C}$ and stimulated for 10 minutes at $22^{\circ} \mathrm{C}$ with $0.2 \% \mathrm{BSA}$, $\mathrm{r}$-VEGF-A, or r-VEGF-C (100 nmol/L with $0.2 \% \mathrm{BSA})$ in the absence or presence of PP2 (an Src inhibitor, $1 \mu \mathrm{mol} / \mathrm{L}$ for 10 minutes). ${ }^{32} \mathrm{IP}_{3}$ levels were assessed by the $\mathrm{IP}_{3}\left[{ }^{3} \mathrm{H}\right]$ kit (Amersham). ${ }^{29}$

Before $\mathrm{Ca}^{2+}$ measurements, NRICCs were incubated for 1 hour at $37^{\circ} \mathrm{C}$ to regenerate the membrane receptors damaged by trypsin digestion. Calcium fluorescence measurements in NRICCs stimulated with $0.2 \% \mathrm{BSA}, 100 \mathrm{nmol} / \mathrm{L}$ r-VEGF-A, or $100 \mathrm{nmol} / \mathrm{L}$ r-VEGF-C for 10 minutes were performed using fluo-3 AM (Molecular Probes, Eugene, OR) and a Fluoroskan Ascent FL (ThermoLabsystems, Helsinki, Finland) microplate reader equipped with 3 injectors. ${ }^{29,33}$ Ionomycin (10 $\mu \mathrm{mol} / \mathrm{L}$ ) was used at the end of each calcium determination to ensure cholangiocyte responsiveness.

To determine the effects of r-VEGF-A and r-VEGF-C on the phosphorylation of protein kinase $\mathrm{C}(\mathrm{PKC})-\alpha$, which regulates cholangiocyte function, ${ }^{18,34-36}$ NRICCs were cultured until $70 \%$ confluent $^{15}$ and stimulated for 90 minutes $^{18}$ with $0.2 \%$ BSA or r-VEGF-A or r-VEGF-C (100 nmol/L with $0.2 \%$ BSA). The expression of total and phosphorylated cholangiocyte PKC- $\alpha$ was evaluated by immunoblots. ${ }^{18}$ After evaluating the phosphorylated PKC- $\alpha$ expression, membranes were stripped to determine total PKC- $\alpha$ protein expression. Stripping buffer from Pierce Biotechnology, Inc. (Rockford, IL) was used according to the manufacturer's instructions.

NRICCs were cultured until $70 \%$ confluent $^{15}$ and stimulated with (1) $0.2 \%$ BSA (basal) for 48 hours or (2) r-VEGF-A or r-VEGF-C (100 nmol/L with $0.2 \% \mathrm{BSA})$ for 48 hours in the absence or presence of 2-hour preincubation with BAPTA/ $\mathrm{AM}$, a $\left[\mathrm{Ca}^{2+}\right]_{\mathrm{i}}$ chelator $^{37}$ (5 $\left.\mu \mathrm{mol} / \mathrm{L}\right)$, Gö6976, a PKC- $\alpha$ inhibitor $^{38}$ (1 $\left.\mu \mathrm{mol} / \mathrm{L}\right)$. Although some studies ${ }^{39}$ refer to Gö6976 as an inhibitor of $\mathrm{Ca}^{2+}$-dependent PKCs rather than PKC- $\alpha$, other studies have shown ${ }^{40-43}$ that Gö6976 is a selective inhibitor of the PKC- $\alpha$ isozyme and PKC- $\beta$ I and does not affect the kinase activity of the $\mathrm{Ca}^{2+}$-independent $\mathrm{PKC}-\delta$, PKC- $\epsilon$, and $\mathrm{PKC}-\zeta$ isozymes even at micromolar levels. Subsequently, we evaluated cholangiocyte proliferation by PCNA immunoblots. To show that r-VEGF-A and rVEGF-C induce an actual increase in cholangiocyte cell number, NRICCs were cultured until $70 \%$ confluent, ${ }^{15}$ seeded into 96-well plates $(10,000$ cells/well), and subsequently stimulated with $0.2 \%$ BSA or r-VEGF-A or r-VEGF-C (100 nmol/L with $0.2 \%$ BSA) for 48 hours. We evaluated cell replication by a cell proliferation assay (MTS assay, CellTiter 96AQueous; Promega Corp, Madison, WI). Changes in cell number were evaluated by measurement of absorbance (490 nm).

NRICCs were cultured until $70 \%$ confluent $^{15}$ and stimulated with $0.2 \%$ BSA or r-VEGF-A or r-VEGF-C (100 nmol/L with $0.2 \%$ BSA) for 48 hours. Subsequently, we evaluated the changes in the phosphorylation of Src (at the Tyr 139 residue), mitogen-activated protein kinases p38 and p42/44 (ERK1/2), and JNK by immunoblots. The intensity of the enhanced chemiluminescence-visualized bands was determined by scanning video densitometry using the ChemiImager 4000 Low Light Imaging System.

\section{Statistical Analysis}

All data are expressed as mean \pm SEM. Differences between groups were analyzed by the Student unpaired $t$ test when 2 groups were analyzed and analysis of variance when more than 2 groups were analyzed, followed by an appropriate post hoc test.

\section{Results}

\section{Cholangiocytes Express VEGFR-2, VEGFR-3, VEGF-A, and VEGF-C and Secrete VEGF}

Bile ducts from normal and BDL rats express VEGFR-2 and VEGFR-3 but not VEGFR-1 (Figure $1 A)$. Immunohistochemistry shows that the expression of VEGFR-2 and VEGFR-3 was higher in bile ducts from BDL rats compared with bile ducts from normal rats $(46.0 \% \pm 3.2 \%[\mathrm{BDL}]$ vs $12.0 \% \pm 1.2 \%$ [normal] VEGFR-2-positive cholangiocytes $[P<.05]$ and $49.0 \% \pm 2.9 \%[\mathrm{BDL}]$ vs $25.0 \% \pm 1.9 \%$ [normal] VEGFR-3-positive cholangiocytes $[P<.05]$ ). Immunofluorescence for VEGFR-1 in BDL liver sections showed the absence of positivity for VEGFR-1 in cholangiocytes (Figure 1B); limited positivity for VEGFR-1 was observed only at the endothelial level (Figure 1B).

Cholangiocytes from normal and BDL rats express the message for VEGFR-2 and VEGFR-3 (Figure 1C). The polymerase chain reaction fragment for rat VEGFR-2 is $98 \%$ homologous to the Norway rat VEGFR-2 sequence ${ }^{44}$ (Gene Bank NM 013062). The polymerase chain reaction fragment for rat VEGFR$3^{22}$ is $100 \%$ homologous to the rat VEGFR-3 sequence $^{22}$ (Gene Bank NM 053652). The expression of GAPDH was similar in cholangiocytes from normal 
A

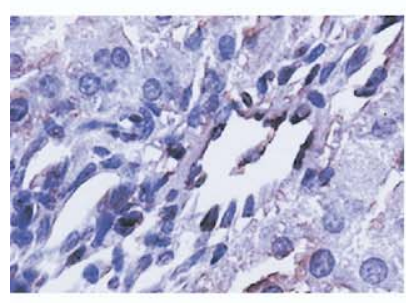

BDL

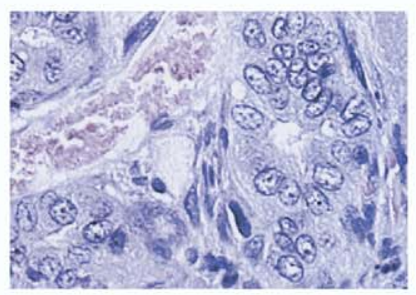

VEGFR-1
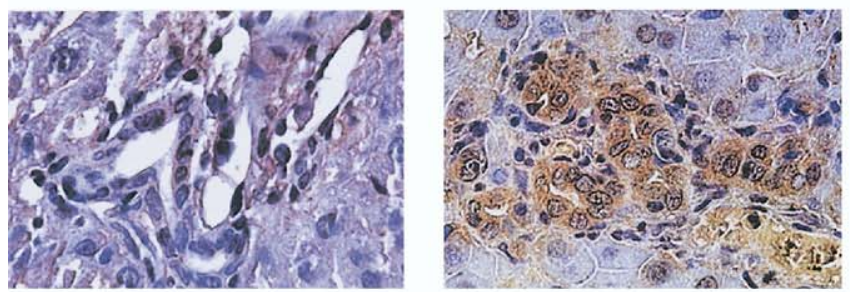

VEGFR-2

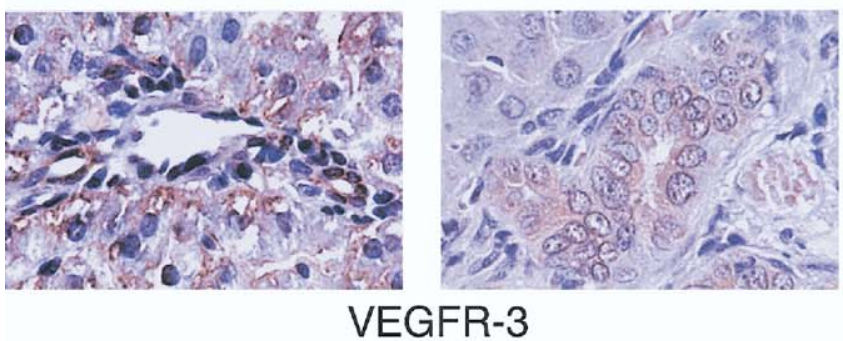

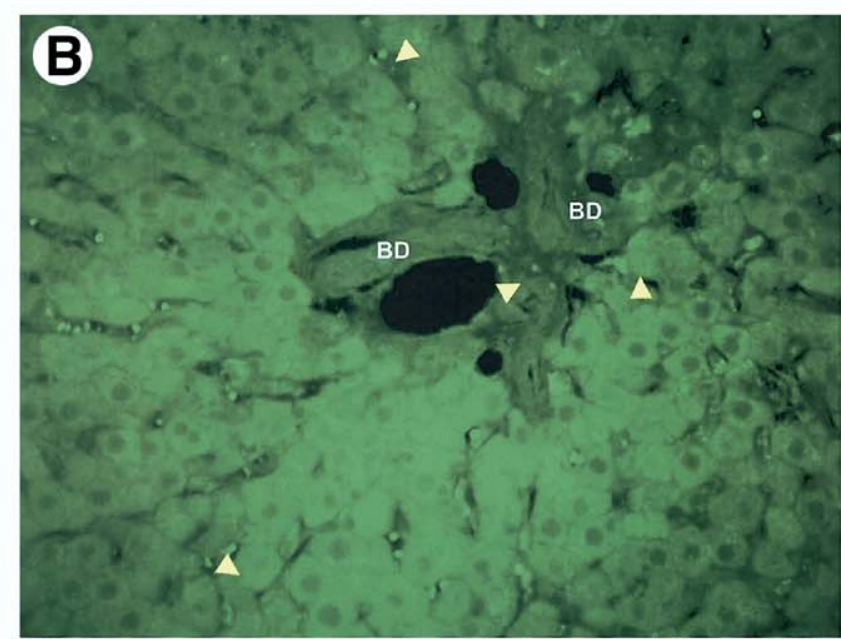

C



VEGFR-2

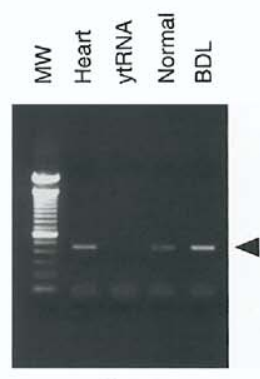

VEGFR-3

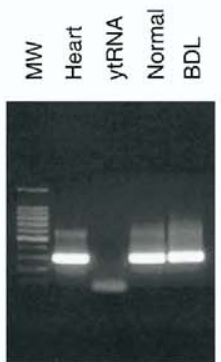

GAPDH

Figure 1. $(A)$ Immunohistochemistry for VEGFR-1, VEGFR-2, and VEGFR-3 in liver sections from normal and BDL rats and $(B)$ immunofluorescence for VEGFR-1 in liver sections from BDL rats. (A) Bile ducts from normal and BDL rats express VEGFR-2 and VEGFR-3 but not VEGFR-1 (original magnification 40×). (B) Immunofluorescence in liver sections from 1-week BDL rats shows the absence of positivity for VEGFR-1 in cholangiocytes. In liver sections, the vessels were negative for VEGFR-1; rare, limited, and mild positivity for VEGFR-1 was observed only at the endothelial level. BD, interlobular bile ducts. Arrowheads indicate Factor VIII-related antigen-positive endothelial cells (original magnification $40 \times$ ). (C) Reverse-transcription polymerase chain reaction analysis showed that cholangiocytes from normal and BDL rats express the message for VEGFR-2 and VEGFR-3. For VEGFR-2 and VEGFR-3, total RNA from rat heart and yeast transfer RNA (ytRNA) were the positive and negative controls, respectively. For GAPDH, total RNA from rat kidney and yeast transfer RNA were the positive and negative controls, respectively. VEGFR-2 mRNA, 337 bp; VEGFR-3 mRNA, 450 bp; GAPDH mRNA, 294 bp. Normal and BDL lanes are cholangiocytes.

and BDL rats (Figure $1 C$ ). By immunoblots, the protein for VEGFR-2 and VEGFR-3 was expressed by cholangiocytes from normal and $\mathrm{BDL}$ rats and NRICCs (not shown).

Immunohistochemistry shows that the expression of VEGF-A and VEGF-C was higher in bile ducts from BDL rats compared with bile ducts from normal rats (Figure 2A). Both normal and BDL cholangiocytes express the mRNA for VEGF-A $(687,565$, and 434 bp) and VEGF-C (243 bp) (Figure $2 B$ ). Similar to previous studies, ${ }^{23} 3$ bands (VEGF 188 -amino acid isoform, $687 \mathrm{bp}$; VEGF 164 -amino acid isoform, 565 bp; and VEGF 120-amino acid isoform, 434 bp) originating from alternative splicing of mRNA for 3 different VEGF-A isoforms were present in normal and BDL cholangiocytes (Figure $2 B$ ). The expression of GAPDH was similar in cholangiocytes from normal and BDL rats (Figure $2 B$ ). Analysis of the sequences indicated $99.8 \%$ homology for the sequence of rat VEGF-A (VEGF 164-amino acid isoform, $565 \mathrm{bp})^{23}$ and $100 \%$ homology for the previously reported sequence of rat VEGF-A (VEGF 120-amino acid isoform, $434 \mathrm{bp})^{23}$ (Gene Bank AY702972). Analysis of the sequences indicated $100 \%$ homology for the sequence of rat VEGF-C. ${ }^{24}$ We found VEGF in the supernatant of primary cultures of normal cholangiocytes and hepatocytes (Figure 2C), indicating that cholangiocytes and hepatocytes secrete VEGF. Following BDL, the amount of VEGF secreted by cholangiocytes into the supernatant increased compared with the VEGF secreted by normal cholangiocytes (Figure $2 C)$. VEGF secretion was decreased in BDL hepatocytes compared with normal hepatocytes (Figure 2C). 


\section{Administration of Anti-VEGF Antibodies Decreases Cholangiocyte Proliferation}

No changes in body weight were observed between BDL rats treated for 1 week with nonimmune serum $(180.57 \pm 6.30 \mathrm{~g})$, anti-VEGF-A (170.53 \pm $3.88 \mathrm{~g})$, or anti-VEGF-C (177.91 $\pm 2.97 \mathrm{~g})$ antibodies. There were no significant differences in the degree of portal inflammation, necrosis, and lobular damage among BDL rats treated with nonimmune serum (1.2 \pm 0.2 [portal inflammation], $1.4 \pm 0.2$ [necrosis], and 1.4

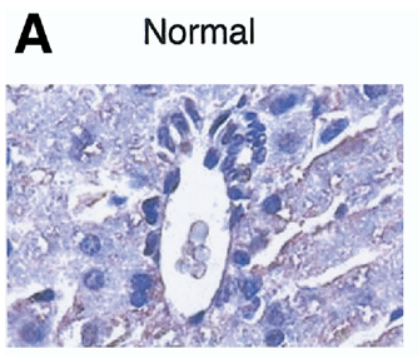

BDL

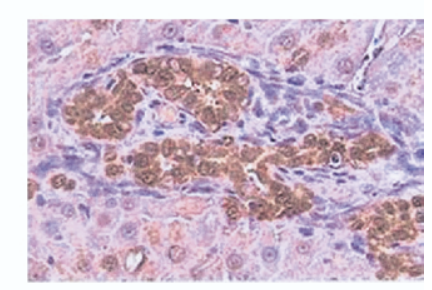

VEGF A
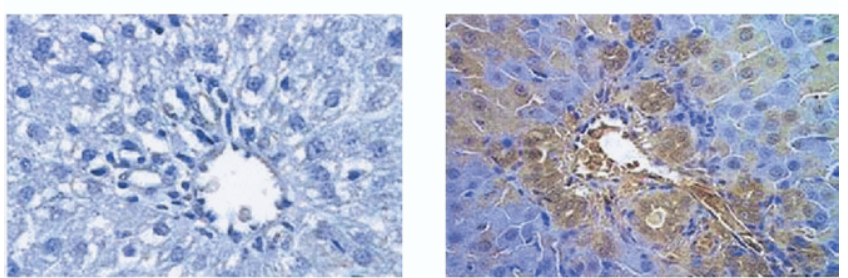

VEGF C

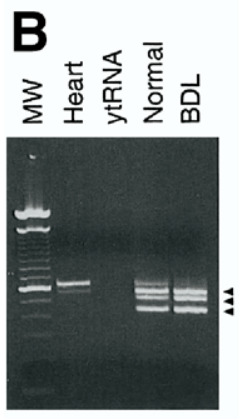

VEGF-A

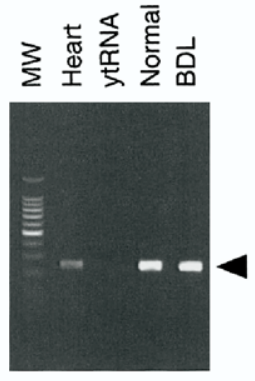

VEGF-C

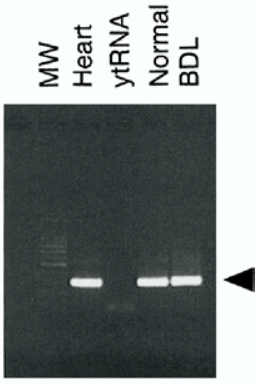

GAPDH
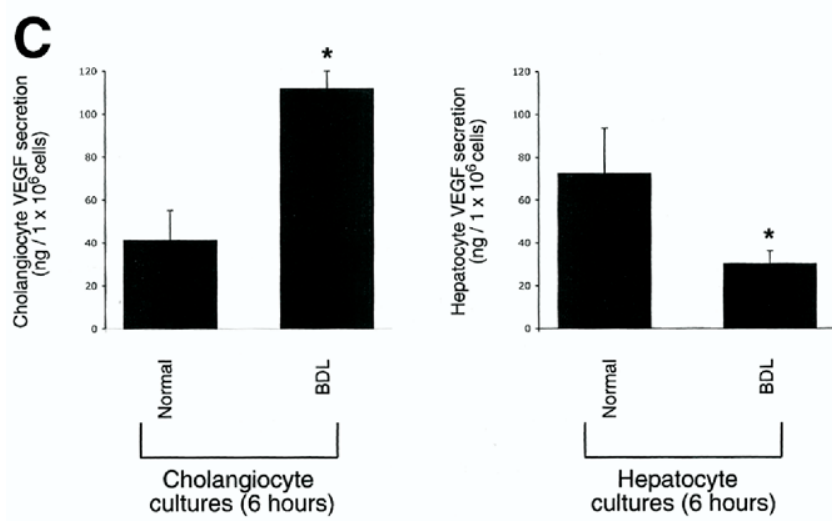

\pm 0.2 [lobular damage]), anti-VEGF-A (1.0 \pm 0.01 [portal inflammation], $1.2 \pm 0.2$ [necrosis], and $1.0 \pm$ 0.01 [lobular damage]), or anti-VEGF-C $(1.2 \pm 0.2$ [portal inflammation], $1.4 \pm 0.2$ [necrosis], and $1.2 \pm$ 0.2 [lobular damage]). The administration of antiVEGF-A or anti-VEGF-C antibody to BDL rats significantly $(P<.05)$ increased the number of apoptotic cholangiocytes per portal tracts compared with BDL rats treated with nonimmune serum $(5.60 \pm 0.51$ [antiVEGF-A antibody] and $4.80 \pm 0.38$ [anti-VEGF-C antibody] vs $2.40 \pm 0.24$ [nonimmune serum]). We have also tested an anti-VEGF antibody reported to immunoneutralize all 3 isoforms of VEGF- $\mathrm{A}^{11,12}$ and found that its administration in BDL rats induced cholangiocyte apoptosis $(8.00 \pm 0.84$ apoptotic cholangiocytes per portal tract). When BDL rats were treated with anti-VEGF-A + C antibody, a further increase of cholangiocyte apoptosis was observed (12.2 \pm 0.97 vs $2.40 \pm 0.24[\mathrm{BDL}$ rats] apoptotic cholangiocytes per portal tract).

Administration of anti-VEGF-A, anti-VEGF-C, or the anti-VEGF antibody (known to immunoneutralize VEGF $)^{11,12}$ to BDL rats induced a similar decrease in the number of PCNA- and CK-19-positive cholangiocytes and GGT-positive ducts compared with BDL rats treated with nonimmune serum (Table 1). The mouse anti-human VEGF antibody (which immunoneutralizes VEGF) ${ }^{11,12}$ was tested by immunohistochemistry to stain positively (not shown) bile ducts from normal and BDL rat liver sections. When BDL rats were treated simultaneously with antiVEGF-A + C antibodies, there was a greater decrease in the

Figure 2. (A) Expression of VEGF-A and VEGF-C by immunohistochemistry in liver sections from normal and BDL rats. The expression of VEGF-A and VEGF-C was higher in bile ducts from BDL rats compared with bile ducts from normal rats (original magnification $25 \times$ ). (B) Normal and BDL cholangiocytes express the mRNA for VEGF-A and VEGF-C. Three bands $(687,565$, and $434 \mathrm{bp})$ originating from alternative splicing of mRNA for 3 different VEGF-A isoforms were present in normal and BDL cholangiocytes. For VEGF-A and VEGF-C, total RNA from rat heart and yeast transfer RNA (ytRNA) were the positive and negative controls, respectively. For GAPDH, total RNA from rat kidney and ytRNA were the positive and negative controls, respectively. Cholangiocytes express the mRNA for VEGF-A $(687,565$, and 434 bp) and VEGF-C (243 bp); GAPDH mRNA, 294 bp. Normal and BDL lanes are cholangiocytes. $(C)$ Measurement of VEGF secretion (nanogram per $1 \times 10^{6}$ cells) into the supernatant of primary cultures (6 hours) of cholangiocytes and hepatocytes from normal and BDL rats. We found VEGF in the supernatant of primary cultures of normal cholangiocytes and hepatocytes. Following BDL, the amount of VEGF secreted by cholangiocytes into the supernatant increased compared with the amount of VEGF secreted by normal cholangiocytes. VEGF secretion significantly decreased in BDL hepatocytes compared with normal hepatocytes. Data are mean \pm SEM of 8 (cholangiocytes) and 16 (hepatocytes) cell preparations. $* P<.05$ vs VEGF secretion of normal cholangiocytes or hepatocytes. 
Table 1. Effect of Administration of Nonimmune Serum or Anti-VEGF Antibodies on the Proliferation of Cholangiocytes of BDL Rats

\begin{tabular}{|c|c|c|c|}
\hline Treatment & $\begin{array}{l}\text { PCNA-positive } \\
\text { cholangiocytes } \\
\quad(n=5)\end{array}$ & $\begin{array}{l}\text { CK-19-positive } \\
\text { cholangiocytes } \\
\quad(n=6)\end{array}$ & $\begin{array}{l}\text { Bile duct volume } \\
\qquad(\%)(n=11)\end{array}$ \\
\hline $\begin{array}{l}\text { BDL + } \\
\text { nonimmune } \\
\text { serum }\end{array}$ & $39.0 \pm 1.9$ & $133.8 \pm 5.7$ & $7.0 \pm 0.6$ \\
\hline $\begin{array}{l}\text { BDL }+ \text { anti-VEGF- } \\
\text { A antibody }\end{array}$ & $17.0 \pm 1.0^{a}$ & $82.7 \pm 1.0^{a}$ & $1.2 \pm 0.2^{a}$ \\
\hline $\begin{array}{l}\text { BDL }+ \text { anti-VEGF- } \\
\text { C antibody }\end{array}$ & $17.0 \pm 1.3^{a}$ & $77.0 \pm 3.3^{a}$ & $1.9 \pm 0.3^{a}$ \\
\hline $\begin{array}{l}\text { BDL }+ \text { anti-VEGF } \\
\text { antibody }\end{array}$ & $11.8 \pm 1.1^{a}$ & $71.3 \pm 2.3^{a}$ & $1.7 \pm 0.2^{a}$ \\
\hline $\begin{array}{l}\text { BDL }+ \text { anti-VEGF- } \\
\mathrm{A}+\mathrm{C} \\
\text { antibodies }\end{array}$ & $6.4 \pm 0.9^{b}$ & $54.5 \pm 3.7^{b}$ & $0.4 \pm 0.06^{b}$ \\
\hline
\end{tabular}

NOTE. Cholangiocyte proliferation was evaluated by measurement of the number of PCNA- and CK-19-positive cholangiocytes and GGTpositive ducts in liver sections. Administration of anti-VEGF-A, antiVEGF-C, or the neutralizing anti-VEGF antibody to BDL rats decreased the number of PCNA- and CK-19-positive cholangiocytes and the number of GGT-positive ducts compared with BDL rats treated with nonimmune serum. When BDL rats were treated simultaneously with both anti-VEGF-A $+C$ antibodies, there was a greater decrease in the number of PCNA- and CK-19-positive cholangiocytes and GGT-positive ducts compared with all the other groups.

${ }^{a} P<.05$ vs its corresponding value of $\mathrm{BDL}$ rats treated with nonimmune serum.

${ }^{b} P<.05$ vs the value of BDL rats treated with nonimmune serum or anti-VEGF antibodies.

number of PCNA- and CK-19-positive cholangiocytes and GGT-positive ducts compared with all the other groups (Table 1). Similarly, there was a significant $(P<.05)$ decrease in PCNA protein expression (expressed as ratio to $\beta$-actin $\times 100$ arbitrary units) in cholangiocytes from BDL rats treated with anti-VEGF-A (40.4 \pm 5.1 arbitrary units, $\mathrm{n}=8)$ or anti-VEGF-C $(44.3 \pm 6.8$ arbitrary units, $\mathrm{n}=$ 8) compared with cholangiocytes from BDL rats treated with nonimmune serum $(65.3 \pm 6.5$ arbitrary units, $\mathrm{n}=$ 8).

To show that following BDL, the proliferation of the PBP only occurs after that of cholangiocytes, we measured the number of PCNA-positive vascular endothelial cells and cholangiocytes in liver sections from rats with BDL for 1 or 2 weeks (Figure 3A). After BDL for 1 week, PCNA was expressed only by proliferating cholangiocytes (and in rare hepatocytes), whereas endothelial cells were negative for PCNA (Figure 3A). In contrast, after BDL for 2 weeks, both cholangiocytes and endothelial cells became positive for PCNA (Figure $3 A$ ). This was confirmed by the immunohistochemical expression of Factor VIII-related antigen (a marker of endothelial cells) ${ }^{28}$ in liver sections from normal, 1-week BDL, and 2 -week BDL rats (Figure 3B). The number of Factor
VIII-related antigen-positive cells increased, in comparison with normal rats, only after 2-week BDL but was unchanged after 1-week BDL, thus confirming that the proliferation of PBP occurs after that of the biliary epithelium.

\section{Effect of Administration of Anti-VEGF-A or Anti-VEGF-C Antibody on Hepatocyte and Cholangiocyte VEGF Secretion and VEGF Serum Concentration}

The secretion of VEGF from cholangiocytes (but not hepatocytes) from BDL rats treated with antiVEGF-A or anti-VEGF-C antibody decreased compared with cholangiocytes from BDL rats treated with nonimmune serum (Table 2). In normal rats, we found a VEGF serum concentration $(226.12 \pm 5.6 \mathrm{ng} / \mathrm{mL} ; \mathrm{n}=4)$ that was similar to that previously described in rats and humans. ${ }^{13,14}$ Following BDL, there was an increase in serum VEGF concentration $(291.04 \pm 10.04$ [BDL] vs $226.12 \pm 5.6 \mathrm{ng} / \mathrm{mL}$ [normal]; $P<.05 ; \mathrm{n}=4$ ).

\section{VEGF Stimulation of Normal Cholangiocyte Proliferation Is Associated With Activation of $\mathrm{IP}_{3} / \mathrm{Ca}^{2+} / \mathrm{PKC}-\alpha$ and Phosphorylation of SrC and ERK1/2}

Administration of r-VEGF-A or r-VEGF-C to normal rats increased cholangiocyte proliferation evaluated by the enhanced number of PCNA- and CK-19-positive cholangiocytes and GGT-positive ducts in liver sections compared with normal rats treated with saline (Table 3).

Consistent with the concept that VEGF stimulates the proliferation of normal cholangiocytes by activation of the $\mathrm{IP}_{3} / \mathrm{Ca}^{2+} / \mathrm{PKC}$ pathway, r-VEGF-A and r-VEGF-C increased cholangiocyte $\mathrm{IP}_{3}$ (Table 4) and $\left[\mathrm{Ca}^{2+}\right]_{\mathrm{i}}$ (Table 5) levels in NRICCs compared with NRICCs treated with BSA. VEGF-A- and VEGF-C-induced increases in $\mathrm{IP}_{3}$ levels were not blocked by the Src inhibitor PP2 (Table 4), a finding that shows that $\mathrm{Src}$ is downstream to $\mathrm{IP}_{3} / \mathrm{Ca}^{2+}$.

In NRICCs, both r-VEGF-A and r-VEGF-C increased the phosphorylation of PKC- $\alpha$ (Table 6), r-VEGF-A and r-VEGF-C increased PCNA protein expression of NRICCs (Table 7), r-VEGF-A- and r-VEGF-C-induced increases in PCNA protein expression of NRICCs were blocked by BAPTA/AM and Gö6976 (Table 7). Both r-VEGF-A and r-VEGF-C increased absorbance (an index of changes in cell number) of NRICCs compared with basal values (Table 6). Furthermore, both r-VEGF-A and r-VEGF-C increased the phosphorylation of the Tyr139 residue (which positively regulates Src activity) ${ }^{45}$ and ERK1/2 of NRICCs in NRICCs (Table 6). Neither r-VEGF-A nor r-VEGF-C altered the phosphorylation of p38 or JNK (not shown). 


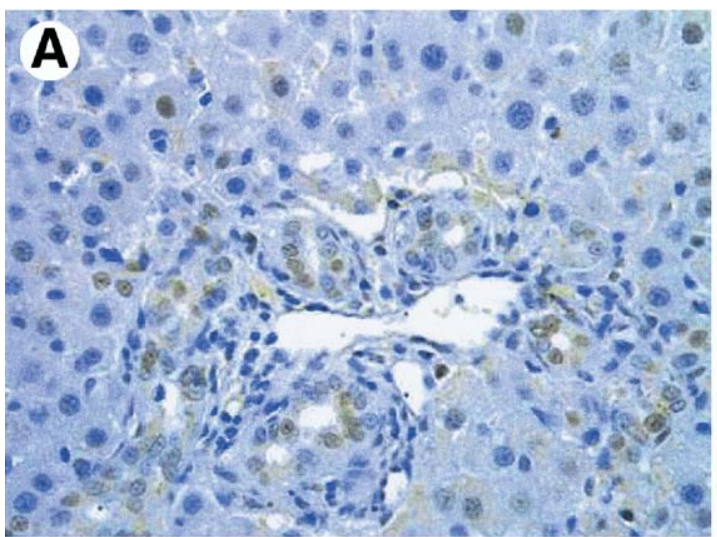

BDL 1 wk

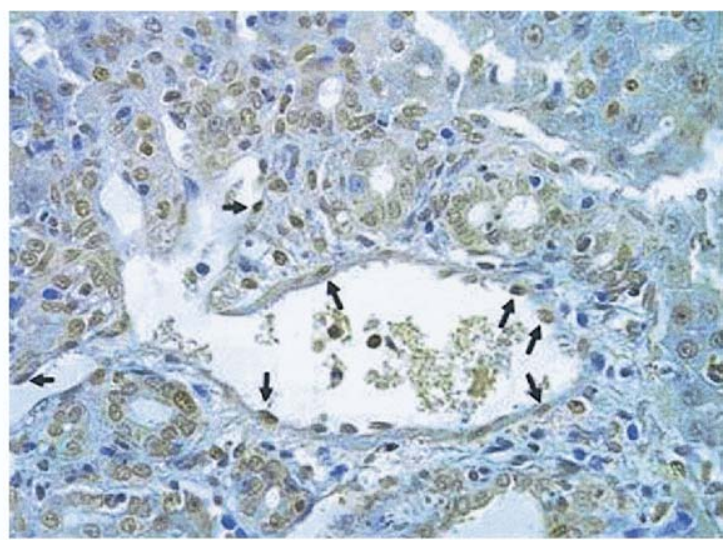

BDL 2 wk
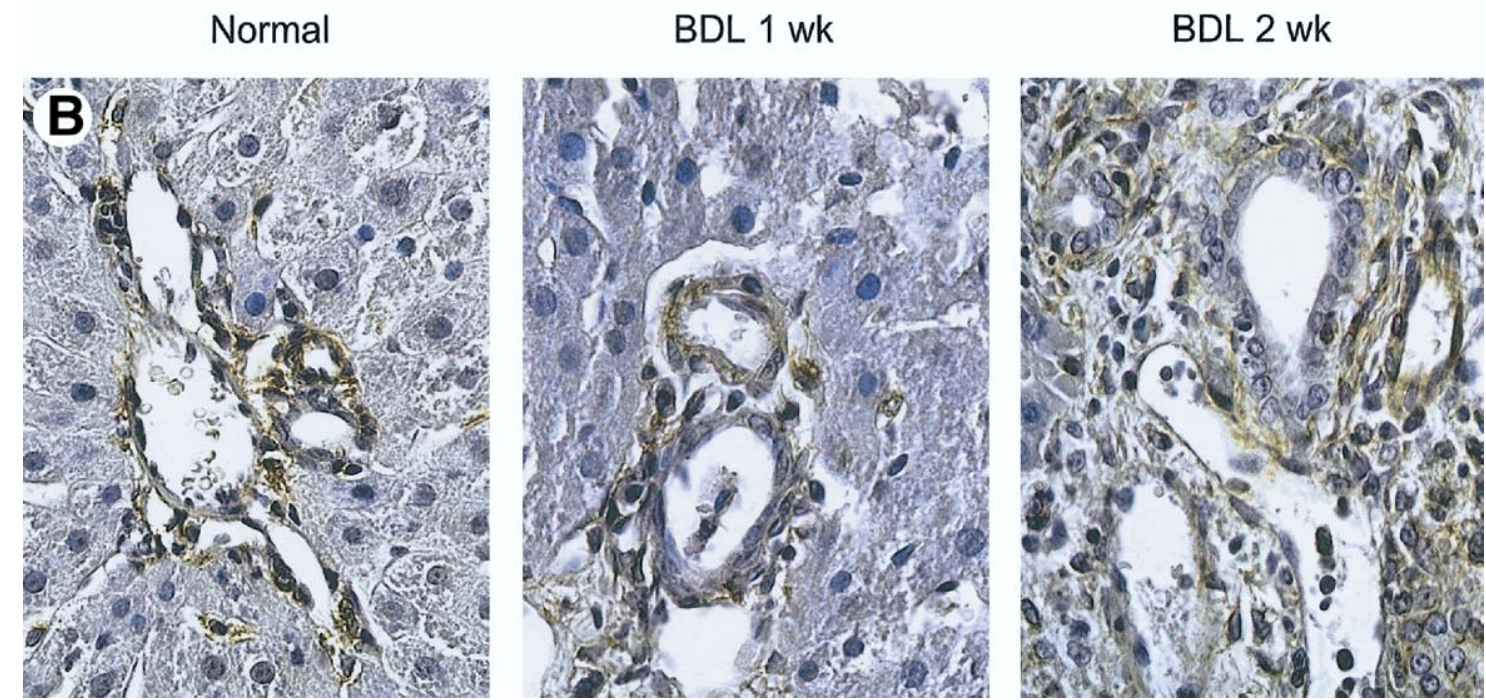

Figure 3. Immunohistochemistry for (A) PCNA in liver sections from 1- and 2-week BDL rats and (B) Factor VIII-related antigen in liver sections from normal, 1-week, and 2-week BDL rats. (A) In 1-week BDL rats, PCNA was expressed only by proliferating cholangiocytes (and in rare hepatocytes), whereas endothelial cells were negative for PCNA. After 2 weeks of BDL, both proliferating cholangiocytes and endothelial cells (arrows) became positive for PCNA. The data demonstrate that bile ducts in vivo proliferate first, then the arterial network (original magnification 40X). (B) The number of Factor VIII-related antigen-positive cells increased, in comparison with normal rats, only after 2-week BDL but was unchanged after 1-week BDL, thus confirming that the proliferation of PBP occurs after that of the biliary epithelium (original magnification $40 \times$ ).

\section{Discussion}

Cholangiocyte proliferation is a typical hallmark of cholangiopathies, where it counteracts the loss/damage of intrahepatic bile ducts to compensate for the structural and functional derangement of the intrahepatic biliary tree. ${ }^{46}$ Proliferating cholangiocytes display enhanced secretory activity, ${ }^{10,20}$ which is important for maintaining a normal ductal secretion despite the loss of damaged bile ducts. ${ }^{46}$ Cholangiocyte proliferation is modulated by a complex system of growth factors, neuropeptides, and hormones. ${ }^{47}$ Most of this information has been achieved in the BDL rat model, which is characterized by cholangiocyte proliferation ${ }^{10,17,18}$ followed by an adaptive proliferation of the PBP. ${ }^{8}$ Similar to previous findings, ${ }^{8}$ our study shows that the proliferation of PBP occurs after that of the intrahepatic biliary epithelium. In support of this concept, we show that in 1-week BDL rats, PCNA is expressed only by proliferating cholangiocytes (and in rare hepatocytes), whereas endothelial cells are negative for PCNA. After 2 weeks of BDL, both cholangiocytes and endothelial cells become positive for PCNA. To determine that following BDL the growth of the PBP is due to the enlargement of bile duct mass, we evaluated the immunohistochemical expression of Factor VIII-related antigen in liver sections from normal and BDL rats. The finding that Factor VIII-related antigen is positive only in endothelial cells, and that the number of the marked cells increases only after 2-week BDL (but not after 1 week) where it correlated with the increased number 
Table 2. Measurement of VEGF Concentration in the Supernatant of Primary Cultures of Hepatocytes and Cholangiocytes From Rats That (Immediately After BDL) Were Treated by a Daily Intraperitoneal Injection of Nonimmune Serum, Anti-VEGF-A Antibody, or Anti-VEGF-C Antibody for 1 Week

\begin{tabular}{|c|c|c|}
\hline Treatment & $\begin{array}{l}\text { Cholangiocyte } \\
\text { VEGF secretion } \\
\left(\mathrm{ng} / 1 \times 10^{6}\right. \\
\text { cells) }\end{array}$ & $\begin{array}{l}\text { Hepatocyte VEGF } \\
\text { secretion (ng/1 } \\
\times 10^{6} \text { cells) }\end{array}$ \\
\hline $\begin{array}{l}\mathrm{BDL}+ \\
\text { nonimmune } \\
\text { serum }\end{array}$ & $142.54 \pm 4.6$ & $31.74 \pm 7.2$ \\
\hline $\begin{array}{l}\text { BDL }+ \text { anti-VEGF- } \\
\mathrm{A} \text { antibody }\end{array}$ & $73.29 \pm 10.0^{a}$ & $37.58 \pm 8.8^{b}$ \\
\hline $\begin{array}{l}\text { BDL }+ \text { anti-VEGF- } \\
\text { C antibody }\end{array}$ & $71.71 \pm 9.6^{a}$ & $32.70 \pm 9.5^{b}$ \\
\hline
\end{tabular}

NOTE. Administration of anti-VEGF-A or anti-VEGF-C antibody reduced cholangiocyte (but not hepatocyte) VEGF secretion compared with cholangiocytes from BDL rats treated with nonimmune serum.

Data are mean \pm SEM of 8 (cholangiocytes) and 16 (hepatocytes) experiments.

${ }^{a} P<.05$ vs VEGF secretion of cholangiocytes from BDL rats treated with nonimmune serum.

${ }^{b}$ Not significant vs secretion of hepatocytes from BDL rats treated with nonimmune serum.

of the proliferated ducts, demonstrates that the expansion of the PBP follows the increases of bile duct mass.

The proliferating bile ducts are characterized by markedly enhanced cholangiocyte secretory and proliferative activities. ${ }^{10,17,18,46}$ Therefore, the adaptive proliferation of the PBP (and its circulating factors, including VEGF) is fundamental to sustain the enhanced functional and nutritional demands of the proliferating biliary tree. ${ }^{8,10,17,18,46}$ Because the proliferation of the PBP follows the increase in the growth of bile ducts, ${ }^{8}$ it is reasonable to suppose that proliferating cholangiocytes modulate the adaptive response of the vascular bed. ${ }^{8}$

Table 3. Effect of Long-term Administration of r-VEGF-A, rVEGF-C, or Saline on the Proliferation of Cholangiocytes of Normal Rats

\begin{tabular}{|c|c|c|c|}
\hline Treatment & $\begin{array}{l}\text { PCNA-positive } \\
\text { cholangiocytes } \\
\quad(n=8)\end{array}$ & $\begin{array}{l}\text { CK-19-positive } \\
\text { cholangiocytes } \\
(n=8)\end{array}$ & $\begin{array}{l}\text { Bile duct volume } \\
\qquad(\%)(n=8)\end{array}$ \\
\hline Normal + saline & $0.5 \pm 0.2$ & $19.4 \pm 3.4$ & $0.4 \pm 0.08$ \\
\hline $\begin{array}{l}\text { Normal + r- } \\
\text { VEGF-A }\end{array}$ & $4.7 \pm 0.5^{a}$ & $32.2 \pm 5.4^{a}$ & $2.4 \pm 0.2^{a}$ \\
\hline $\begin{array}{l}\text { Normal }+r- \\
\text { VEGF-C }\end{array}$ & $5.7 \pm 0.7^{a}$ & $37.7 \pm 7.0^{a}$ & $2.0 \pm 0.1^{a}$ \\
\hline
\end{tabular}

NOTE. Cholangiocyte proliferation was evaluated by measurement of the number of PCNA- and CK-19-positive cholangiocytes and GGTpositive ducts in liver sections from the selected groups of animals. Administration of $r$-VEGF-A or $r-V E G F-C$ increased the number of PCNAand CK-19-positive cholangiocytes and GGT-positive ducts compared with normal rats treated with saline for 1 week. Data are mean \pm SE. ${ }^{a} P<.05$ vs its corresponding value of normal rats treated with saline.
Table 4. Effect of $r-V E G F-A$ and $r-V E G F-C$ on $I_{3}$ Levels of NRICCs

\begin{tabular}{lc}
\hline \multicolumn{1}{c}{ Treatment } & $\mathrm{IP}_{3}$ levels $\left(\mathrm{pmol} / 1 \times 10^{6}\right.$ cells $)$ \\
\hline Basal & $0.18 \pm 0.02$ \\
r-VEGF-A & $0.32 \pm 0.03^{a}$ \\
PP2 + r-VEGF-A & $0.34 \pm 0.01^{a}$ \\
r-VEGF-C & $0.31 \pm 0.08^{a}$ \\
PP2 + r-VEGF-C & $0.29 \pm 0.02^{a}$ \\
\hline
\end{tabular}

NOTE. Measurement of $\mathrm{IP}_{3}$ levels of NRICCs stimulated at room temperature for 10 minutes with $0.2 \%$ BSA or r-VEGF-A or r-VEGF-C $(100 \mathrm{nmol} / \mathrm{L}$ with $0.2 \% \mathrm{BSA})$ in the absence or presence of preincubation with PP2 (1 $\mu \mathrm{mol} / \mathrm{L}$ for 10 minutes). Both r-VEGF-A and $\mathrm{r}$ VEGF-C increased cholangiocyte IP 3 levels in NRICCs compared with NRICCs treated with $0.2 \%$ BSA. VEGF-A-and VEGF-C-induced increases in $\mathrm{IP}_{3}$ levels were not blocked by the Src inhibitor PP2. Data are mean \pm SEM of 7 experiments.

${ }^{a} P<0.05$ vs its corresponding value of NRICCs treated with $0.2 \%$ BSA.

With this background, we evaluated the role of VEGF in modulating cholangiocyte pathophysiology in BDL rats. Our study has clinical implications, because in human cholangiopathies alterations of the PBP have been described to be associated with bile duct damage and to condition the development and progression of the disease. ${ }^{48,49}$ On the other hand, studies suggest that the activation of the VEGF system represents a protective mechanism during experimental liver damage, suggesting that regulation of VEGF hepatic synthesis or VEGF receptors could represent a potential therapeutic strategy for the management of liver injury. ${ }^{50}$

We showed that (1) VEGFR-2 and VEGFR-3 are present in normal cholangiocytes and (2) the expression of VEGFR-2 and VEGFR-3 is increased in cholangiocytes following BDL. VEGF-A and VEGF-C protein were expressed in normal cholangiocytes, and their expression increased after BDL. Furthermore, VEGF is secreted by cholangiocytes and hepatocytes, because in the medium of short-term cultures of normal cholangiocytes and hepatocytes we found significant amounts of

Table 5. Effect of r-VEGF-A and r-VEGF-C on $\left[\mathrm{Ca}^{2+}\right]_{i}$ Levels of NRICCs

\begin{tabular}{ll}
\hline Treatment & {$\left[\mathrm{Ca}^{2+}\right]_{1}$ levels $(\mathrm{nmol} / \mathrm{L})$} \\
\hline Basal & $197.59 \pm 1.85(\mathrm{n}=5)$ \\
r-VEGF-A & $301.10 \pm 9.87^{a} \quad(\mathrm{n}=5)$ \\
r-VEGF-C & $294.06 \pm 10.06^{a}(\mathrm{n}=5)$ \\
\hline
\end{tabular}

NOTE. Calcium fluorescence measurements in NRICCs stimulated with $0.2 \% \mathrm{BSA}$ or $100 \mathrm{nmol} / \mathrm{L}$ r-VEGF-A or $\mathrm{r}$-VEGF-C for 10 minutes were performed using fluo-3AM (Molecular Probes) and a Fluoroskan Ascent FL (ThermoLabsystems) microplate reader equipped with 3 injectors. Both r-VEGF-A and r-VEGF-C increased cholangiocyte $\left[\mathrm{Ca}^{2+}\right]$ levels in NRICCs compared with NRICCs treated with 0.2\% BSA. Data are mean \pm SEM

${ }^{a} P<.05$ vs its corresponding basal value. 
Table 6. Effect of r-VEGF-A and r-VEGF-C on the Growth of NRICCs and Phosphorylation of PKC- $\alpha$, Src139, and ERK1/2 in NRICCs

\begin{tabular}{|c|c|c|c|c|c|}
\hline Treatment & $\begin{array}{l}\text { Cell proliferation } \\
\text { (MTS, absorbance } \\
\text { at } 490 \mathrm{~nm}) \\
(\mathrm{n}=8)\end{array}$ & $\begin{array}{l}\text { pPKC- } \alpha \text { to } \\
\text { tPKC- } \alpha \text { ratio } \\
\times 100 \\
(n=6)\end{array}$ & $\begin{array}{l}\text { pSrc139 } \\
\text { to } t \text { Src ratio } \\
\times 100 \\
(n=7)\end{array}$ & $\begin{array}{l}\text { pERK1 to } \\
\text { tERK1 ratio } \\
\times 100 \\
(n=10)\end{array}$ & $\begin{array}{l}\text { pERK2 to } \\
\text { tERK2 ratio } \\
\times 100 \\
(n=10)\end{array}$ \\
\hline Basal (0.2\% BSA) & $0.14 \pm 0.01$ & $37.1 \pm 5.3$ & $121.1 \pm 13.8$ & $165.7 \pm 18.7$ & $171.7 \pm 20.6$ \\
\hline r-VEGF-A (100 nmol/L) & $0.21 \pm 0.01^{a}$ & $51.3 \pm 5.4^{a}$ & $164.3 \pm 16.5^{a}$ & $216.1 \pm 22.0^{a}$ & $243.6 \pm 22.3^{a}$ \\
\hline r-VEGF-C (100 nmol/L) & $0.22 \pm 0.03^{a}$ & $55.1 \pm 5.7^{a}$ & $172.7 \pm 18.9^{a}$ & $212.5 \pm 21.1^{a}$ & $233.2 \pm 19.6^{a}$ \\
\hline
\end{tabular}

NOTE. r-VEGF-A and r-VEGF-C increased (1) proliferation of NRICCs evaluated by MTS assay (increased absorbance at $490 \mathrm{~nm}$ ) compared with its basal value and (2) phosphorylation of PKC- $\alpha$, Src139, and ERK1/2 of NRICCs.

aP $<.05$ vs its corresponding value of NRICCs treated with $0.2 \%$ BSA.

VEGF. Following BDL, VEGF secretion increased in the medium of proliferating cholangiocytes (but not hepatocytes) isolated from BDL rats. Therefore, these findings indicate that the VEGF system (ligands and receptors) is activated and amplified in proliferating cholangiocytes after BDL. The VEGF concentration we found in the rat serum (nanomolar range) or in the supernatant of primary cultures of purified normal rat cholangiocytes $(41.15 \pm 14.04 \mathrm{ng} / \mathrm{mL})$ was much higher than that reported by Nichols et $\mathrm{al}^{51}$ in cyst fluid (average, 0.849 $\mathrm{ng} / \mathrm{mL}$ ) of patients with autosomal dominant polycystic kidney disease or in bile $(0.27 \mathrm{ng} / \mathrm{mL})$ of control subjects. However, VEGF secretion from the apical side of cholangiocytes into bile or cyst fluid likely represents only a portion of total secreted VEGF and this, other than species differences (human vs rats), could explain the divergence with respect to the study by Nichols et al. Furthermore, the serum levels of VEGF found in our study in normal rats were similar to that previously reported in rat and human serum. ${ }^{13,14}$

Table 7. In Vitro Effect of r-VEGF-A or r-VEGF-C on PCNA Protein Expression of NRICCs

\begin{tabular}{lc}
\hline \multicolumn{1}{c}{ Treatment } & $\begin{array}{c}\text { PCNA to } \beta \text {-actin } \\
\text { ratio } \times 100\end{array}$ \\
\hline Basal & $94.4 \pm 4.4$ \\
r-VEGF-A & $121.6 \pm 14.4^{a}$ \\
BAPTA/AM + r-VEGF-A & $97.9 \pm 7.0$ \\
Gö6976 + r-VEGF-A & $96.1 \pm 5.9$ \\
r-VEGF-C & $118.9 \pm 13.3^{a}$ \\
BAPTA/AM + r-VEGF-C & $103.9 \pm 5.9$ \\
Gö6976 + r-VEGF-C & $105.7 \pm 5.1^{a}$ \\
\hline
\end{tabular}

NOTE. In vitro effect of r-VEGF-A or r-VEGF-C on PCNA protein expression of NRICCs treated in vitro with $0.2 \%$ BSA (basal) or $r$-VEGF-A or $r$-VEGF-C $(100 \mathrm{~nm})$ in the absence or presence of BAPTA/AM (5 $\mu \mathrm{mol} / \mathrm{L})$, and Gö6976 (1 $\mu \mathrm{mol} / \mathrm{L})$. Both r-VEGF-A and r-VEGF-C increased PCNA protein expression of NRICCs. r-VEGF-Aor $\mathrm{r}$-VEGF-C-induced increases in PCNA protein expression were blocked by BAPTA/AM, and Gö6976. Data are mean \pm SEM of 11 experiments.

${ }^{a} P<.05$ vs its corresponding value of NRICCs treated with $0.2 \%$ BSA.
To evaluate whether VEGF and related receptors regulate cholangiocyte proliferation, we injected BDL rats (immediately after BDL) for 1 week with different antibodies against VEGF. Proliferation of cholangiocytes was inhibited by the in vivo administration of different antiVEGF antibodies, a finding that supports the concept that VEGF, secreted by cholangiocytes, modulates (through an autocrine mechanism) intrahepatic ductal mass. We tested 2 antibodies (anti-VEGF-A and antiVEGF-C) that bind the functional domains of VEGF-A and VEGF-C, respectively (as evaluated in Santa Cruz data sheets and http://www.ebi.uniprot.org) and an additional antibody (anti-VEGF) reported to block all 3 isoforms of VEGF-A identified in cholangiocytes. ${ }^{11,12}$ In addition, when anti-VEGF-A and anti-VEGF-C antibodies were administered together, the inhibitory effects on cholangiocyte proliferation were higher than that obtained by each individual antibody. Because VEGF-A and VEGF-C activate similar signaling pathways, it should be expected that VEGF-A would be able to compensate in case of VEGF-C blockade and vice versa. In contrast, we found that the inhibition of either VEGF-A or VEGF-C induces the same effects. This could suggest a cross-reaction of the anti-VEGF-A and anti-VEGF-C antibodies, but this is only partial given the additional inhibitory effect of the 2 antibodies administered together in BDL rats.

The fact that, similar to other studies, ${ }^{50,52}$ hepatocytes secrete VEGF raises the possibility that cholangiocyte growth may be also regulated by a paracrine mechanism through hepatocyte VEGF secretion. However, because (1) hepatocyte VEGF secretion decreases following BDL and (2) hepatocyte VEGF secretion does not change following the administration of anti-VEGF antibodies, we propose that regulation of BDL cholangiocyte growth occurs mainly by an autocrine mechanism (by secretion of cholangiocyte VEGF secretion), although a paracrine mechanism (by hepatocyte secretion) cannot be ruled out completely by this study. Our finding that VEGF con- 
centration decreases in the serum of BDL rats treated with anti-VEGF-A or anti-VEGF-C antibody compared with the serum of BDL rats treated with nonimmune serum suggests that the block of extracellular VEGF leads to impaired cholangiocyte proliferation, which is then followed by a decreased VEGF secretion. This should also explain why cholangiocytes isolated from BDL rats treated with anti-VEGF antibodies display a lower VEGF secretion in the supernatant even in the absence of anti-VEGF antibodies in the medium.

Furthermore, we injected normal rats with r-VEGF-A or r-VEGF-C and found an increase in cholangiocyte proliferation. To directly evaluate the role and mechanisms of action by which VEGF modulates cholangiocyte proliferation, we incubated NRICCs ${ }^{15}$ (which, similar to freshly isolated cholangiocytes, express VEGFR-2 and VEGFR-3) with r-VEGF-A or r-VEGF-C and showed the ability of VEGF to induce in vitro cholangiocyte proliferation. Next, to elucidate the signaling transduction pathways involved, we performed in vitro studies in NRICCs showing that VEGF increases intracellular $\mathrm{IP}_{3}$ and $\mathrm{Ca}^{2+}$ levels and phosphorylation of PKC- $\alpha$. VEGF receptors belong to the family of membrane-bound tyrosine kinase receptors, and therefore their intracellular signaling is mediated by tyrosine phosphorylation of several intracellular and membrane-bound proteins. ${ }^{53}$ However, in many studies, it has been shown that VEGF also induces activation of PLC- $\gamma,{ }^{54,55}$ leading to generation of diacylglycerol and $\mathrm{IP}_{3}$ and subsequent PKC activation by an increase in intracellular $\mathrm{Ca}^{2+}$. This is particularly important in the modulation of endothelial cell proliferation because PKC blockers inhibit VEGFinduced endothelial cell proliferation. ${ }^{56}$ In NRICCs, we observed that VEGF increased intracellular $\mathrm{IP}_{3}$ and $\mathrm{Ca}^{2+}$ levels and enhanced activation of the $\mathrm{Ca}^{2+}$-dependent PKC- $\alpha$ and Src. In our previous reports, ${ }^{29,34,36,57,58}$ we showed that the calcium dynamics of cholangiocytes are in general slower and not characterized by a calcium spike. ${ }^{34,36,57}$ The method that we currently use results in calcium measurements that are an average signal of 400,000 cells rather than typical single-cell measurements. This approach gives us similar data ${ }^{29,58}$ to that obtained with measurements, which were made in single cells loaded with Fluo-3AM. ${ }^{34,36,57}$ Because the measurements are taken in a large number of cells, the cellular response to VEGF-A or VEGF-C is not synchronized in the studies. Thus, any peak(s) present will be muted and spread out over time, which is a factor contributing to the slow drift observed. The slow ionomycin response is again a factor of an average signal of many cells.

We also found that ERK1/2 (but not p38 and JNK) phosphorylation was enhanced in isolated cholangiocytes incubated with VEGF. This latter result suggests a key role of the mitogen-activated protein kinase isoform, ERK1/2, in the activation of the proliferative machinery by VEGF, similar to other agents inducing cholangiocyte proliferation, such as estrogens and insulin-like growth factor I. ${ }^{32,59}$ On the other hand, in many different cell types, synergistic effects of VEGF, estrogens, and insulin-like growth factor I on modulation of cell proliferation have been described with convergence of the different signaling pathways at the level of the ERK system. ${ }^{60,61}$ We found that VEGF increased Tyr139 phosphorylation, which positively regulates Src activity ${ }^{45}$ in NRICCs. Activation of Src has often been described in endothelial cells stimulated to proliferate by VEGF. ${ }^{4} \mathrm{Src}$ is an adapter protein linked with G-protein-coupled receptors, and its phosphorylation has been considered an early step in VEGF signaling that determines the downstream activation of PLC- $\gamma$ and therefore $\mathrm{IP}_{3}$ formation and $\mathrm{Ca}^{2+}$ mobilization. ${ }^{62}$ On the other hand, Src activation could represent an early step in the activation of the RAS/RAF/MEK/ERK cascade. Our findings indicate that, in cholangiocytes, activation of Src is a downstream event occurring after $\mathrm{IP}_{3}$ and $\mathrm{Ca}^{2+}$ mobilization because the specific Src inhibitor, PP2, did not influence VEGFinduced increases in $\mathrm{IP}_{3}$ levels in NRICCs.

In conclusion, our study indicates that VEGF, likely by an autocrine mechanism, plays a major role in modulating cholangiocyte proliferation in response to cholestasis. The study suggests that administration of VEGF analogues or neutralizing anti-VEGF antibodies may represent an important strategy for the regulation of cholangiocyte proliferation/loss during the course of cholangiopathies.

\section{References}

1. Clauss M. Molecular biology of the VEGF and the VEGF receptor family. Semin Thromb Hemost 2000;26:561-569.

2. Ferrara N, Gerber HP, LeCouter J. The biology of VEGF and its receptors. Nat Med 2003;9:669-676.

3. Larrivee B, Karsan A. Signaling pathways induced by vascular endothelial growth factor. Int J Mol Med 2000;5:447-456.

4. Zachary I. VEGF signalling: integration and multi-tasking in endothelial cell biology. Biochem Soc Trans 2003;31:1171-1177.

5. Uchida S, Sakai A, Kudo H, Otomo H, Watanuki M, Tanaka M, Nagashima M, Nakamura T. Vascular endothelial growth factor is expressed along with its receptors during the healing process of bone and bone marrow after drill-hole injury in rats. Bone 2003; 32:491-501.

6. Schoeffner DJ, Matheny SL, Akahane T, Factor V, Berry A, Merlino G, Thorgeirsson UP. VEGF contributes to mammary tumor growth in transgenic mice through paracrine and autocrine mechanisms. Lab Invest 2005;85:608-623.

7. Sartelet H, Decaussin M, Devouassoux G, Nawrocki-Raby B, Brichon PY, Brambilla C, Brambilla E. Expression of vascular endothelial growth factor (VEGF) and its receptors (VEGF-R1 [FIt-1] and VEGF-R2 [KDR/Flk-1]) in tumorlets and in neuroendocrine cell hyperplasia of the lung. Hum Pathol 2004;35:1210-1217. 
8. Gaudio E, Onori P, Pannarale L, Alvaro D. Hepatic microcirculation and peribiliary plexus in experimental biliary cirrhosis: a morphological study. Gastroenterology 1996;111:1118-1124.

9. Gaudio E, Onori P, Pannarale L. Microcirculation of the extrahepatic biliary tree: a scanning electron microscopy study of corrosion casts. J Anat 1993;182:37-44.

10. Alpini G, Lenzi R, Sarkozi L, Tavoloni N. Biliary physiology in rats with bile ductular cell hyperplasia. Evidence for a secretory function of proliferated bile ductules. J Clin Invest 1988;81:569578.

11. Rowe AJ, Morris KD, Bicknell R, Fraser HM. Angiogenesis in the corpus luteum of early pregnancy in the marmoset and the effects of vascular endothelial growth factor immunoneutralization on establishment of pregnancy. Biol Reprod 2002;67:11801188.

12. Fraser HM, Dickson SE, Lunn SF, Wulff C, Morris KD, Carroll VA, Bicknell R. Suppression of luteal angiogenesis in the primate after neutralization of vascular endothelial growth factor. Endocrinology 2000;141:995-1000.

13. Yin R, Feng J, Yao Z. Dynamic changes of serum vascular endothelial growth factor levels in a rat myocardial infarction model. Chin Med Sci J 2000;15:154-156.

14. Assy N, Paizi M, Gaitini D, Baruch Y, Spira G. Clinical implication of VEGF serum levels in cirrhotic patients with or without portal hypertension. World J Gastroenterol 1999;5:296-300.

15. Alpini G, Phinizy JL, Glaser S, Francis H, Benedetti A, Marucci L, LeSage G. Development and characterization of secretin-stimulated secretion in cultured rat cholangiocytes. Am J Physiol 2003; 284:G1066-G1073.

16. Rutenburg AM, Kim H, Fischbein JW, Hanker JS, Wasserkrug HL, Seligman AM. Histochemical and ultrastructural demonstration of $\gamma$-glutamyl transpeptidase activity. J Histochem Cytochem 1969;17:517-526.

17. Alpini G, Glaser S, Ueno Y, Pham L, Podila PV, Caligiuri A, LeSage G, LaRusso NF. Heterogeneity of the proliferative capacity of rat cholangiocytes after bile duct ligation. Am J Physiol 1998;274: G767-G775.

18. Glaser S, Benedetti A, Marucci L, Alvaro D, Baiocchi L, Kanno N, Caligiuri A, Phinizy JL, Chowdhury U, Papa E, LeSage G, Alpini G. Gastrin inhibits cholangiocyte growth in bile duct ligated rats by interaction with CCK-B/gastrin receptors via $\mathrm{IP}_{3^{-}}, \mathrm{Ca}^{2+}$, and PKC $\alpha$-dependent mechanisms. Hepatology 2000;32:17-25.

19. Ishii M, Vroman B, LaRusso NF. Isolation and morphological characterization of bile duct epithelial cells from normal rat liver. Gastroenterology 1989;97:1236-1247.

20. LeSage G, Glaser S, Gubba S, Robertson WE, Phinizy JL, Lasater J, Rodgers R, Alpini G. Regrowth of the rat biliary tree after $70 \%$ partial hepatectomy is coupled to increased secretin-induced ductal bile secretion. Gastroenterology 1996;111:1633-1644.

21. Sato T, El-Assal ON, Ono T, Yamanoi A, Dhar DK, Nagasue N. Sinusoidal endothelial cell proliferation and expression of angiopoietin/Tie family in regenerating rat liver. J Hepatol 2001;34: 690-698.

22. Zhang X, Groopman JE, Wang JF. Extracellular matrix regulates endothelial functions through interaction of VEGFR-3 and integrin alpha5beta1. J Cell Physiol 2005;202:205-214.

23. Rosmorduc O, Wendum D, Corpechot C, Galy B, Sebbagh N, Raleigh J, Housset C, Poupon R. Hepatocellular hypoxia-induced vascular endothelial growth factor expression and angiogenesis in experimental biliary cirrhosis. Am J Pathol 1999;155:1065-1073.

24. Kirkin V, Mazitschek R, Krishnan J, Steffen A, Waltenberger J, Pepper MS, Giannis A, Sleeman JP. Characterization of indolinones which preferentially inhibit VEGF-C- and VEGF-D-induced activation of VEGFR-3 rather than VEGFR-2. Eur J Biochem 2001; 268:5530-5540.

25. Fort P, Marty L, Piechaczyk M, el Sabrouty S, Dani C, Jeanteur P, Blanchard JM. Various rat adult tissues express only one major
mRNA species from the glyceraldehyde-3-phosphate-dehydrogenase multigenic family. Nucleic Acids Res 1985;13:1431-1342.

26. LeSage G, Glaser S, Marucci L, Benedetti A, Phinizy JL, Rodgers R, Caligiuri A, Papa E, Tretjak Z, Jezequel AM, Holcomb LA, Alpini $G$. Acute carbon tetrachloride feeding induces damage of large but not small cholangiocytes from BDL rat liver. Am J Physiol 1999;276:G1289-G1301.

27. LeSage G, Glaser S, Ueno Y, Alvaro D, Baiocchi L, Kanno N, Phinizy JL, Francis H, Alpini G. Regression of cholangiocyte proliferation after cessation of ANIT feeding is associated with increased apoptosis. Am J Physiol 2001;281:G182-G190.

28. Harach HR, Jasani B, Williams ED. Factor VIII as a marker of endothelial cells in follicular carcinoma of the thyroid. J Clin Pathol 1983;36:1050-1054.

29. Glaser S, Alvaro D, Roskams T, Phinizy JL, Stoica G, Francis H, Ueno Y, Barbaro B, Marzioni M, Mauldin J, Rashid S, Mancino MG, LeSage G, Alpini G. Dopaminergic inhibition of secretinstimulated choleresis by increased PKC- $\alpha$ expression and decrease of PKA activity. Am J Physiol 2003;284:G683-G694.

30. Brock TA, Dvorak HF, Senger DR. Tumor-secreted vascular permeability factor increases cytosolic $\mathrm{Ca}^{2+}$ and von Willebrand factor release in human endothelial cells. Am J Pathol 1991;138: 213-221.

31. Faehling M, Kroll J, Fohr KJ, Fellbrich G, Mayr U, Trischler G, Waltenberger J. Essential role of calcium in vascular endothelial growth factor A-induced signaling: mechanism of the antiangiogenic effect of carboxyamidotriazole. FASEB J 2002;16:1805-1807.

32. Alvaro D, Onori P, Metalli VD, Svegliati-Baroni G, Folli F, Franchitto A, Alpini G, Mancino MG, Attili AF, Gaudio E. Intracellular pathways mediating estrogen-induced cholangiocyte proliferation in the rat. Hepatology 2002;36:297-304.

33. Kassack M, Hofgen B, Lehmann J, Eckstein N, Quillan J, Sadee W. Functional screening of $\mathrm{G}$ protein-coupled receptors by measuring intracellular calcium with a fluorescence microplate reader. J Biomol Screen 2002;7:233-246.

34. Alpini G, Baiocchi L, Glaser S, Ueno Y, Marzioni M, Francis H, Phinizy JL, Angelico M, LeSage G. Ursodeoxycholate and tauroursodeoxycholate inhibit cholangiocyte growth and secretion of BDL rats through activation of PKC alpha. Hepatology 2002;35: 1041-1052.

35. Alpini G, Ueno Y, Glaser S, Phinizy JL, Francis H, LeSage G. Bile acid feeding stimulates proliferative activity of both small and large cholangiocytes through activation and membrane translocation of protein kinase C alpha. Hepatology 2001;34:868-876.

36. LeSage G, Marucci L, Alvaro D, Glaser S, Benedetti A, Marzioni M, Patel T, Francis H, Phinizy JL, Alpini G. Insulin inhibits secretininduced ductal secretion by activation of PKC alpha and inhibition of PKA activity. Hepatology 2002;36:641-651.

37. Kanno N, Glaser S, Chowdhury U, Phinizy JL, Baiocchi L, Francis H, LeSage G, Alpini G. Gastrin inhibits cholangiocarcinoma growth through increased apoptosis by activation of $\mathrm{Ca}^{2+}$-dependent protein kinase C-alpha. J Hepatol 2001;34:284-291.

38. Morales-Mulia S, Cardin V, Torres-Marquez ME, Crevenna A, Pasantes-Morales $\mathrm{H}$. Influence of protein kinases on the osmosensitive release of taurine from cerebellar granule neurons. Neurochem Int 2001;38:153-161.

39. Pula G, Crosby D, Baker J, Poole AW. Functional interaction of PKCalpha with the tyrosine kinases Syk and Src in human platelets. J Biol Chem 2005;280:7194-7205.

40. Martiny-Baron G, Kazanietz MG, Mischak H, Blumberg PM, Kochs G, Hug H, Marme D, Schachtele C. Selective inhibition of protein kinase C isozymes by the indolocarbazole Gö6976. J Biol Chem 1993;268:9194-9197.

41. Wenzel-Seifert K, Schachtele C, Seifert R. N-protein kinase C isoenzymes may be involved in the regulation of various neutrophil functions. Biochem Biophys Res Commun 1994;200:15361543. 
42. Zhu D, Jiang X, Wu X, Tian F, Mearow K, Lipsky RH, Marini AM. Inhibition of protein kinase $C$ promotes neuronal survival in low potassium through an Akt-dependent pathway. Neurotox Res 2004;6:281-289.

43. Huigsloot M, Tijdens RB, van de Water B. Inhibition of protein kinase $C$ alpha enhances anticancer agent-induced loss of anchorage-independent growth regardless of protection against apoptosis by Bcl-2. Mol Pharmacol 2003;64:965-973.

44. Wen Y, Edelman JL, Kang T, Zeng N, Sachs G. Two functional forms of vascular endothelial growth factor receptor-2/Flk-1 mRNA are expressed in normal rat retina. J Biol Chem 1998;273: 2090-2097.

45. Stephens LR, Anderson KE, Hawkins PT. Src family kinases mediate receptor-stimulated, phosphoinositide 3-kinase-dependent, tyrosine phosphorylation of dual adaptor for phosphotyrosine and 3-phosphoinositides-1 in endothelial and B cell lines. J Biol Chem 2001;276:42767-42773.

46. Alpini G, Prall RT, LaRusso NF. The pathobiology of biliary epithelia. In: Arias IM, Boyer JL, Chisari FV, Fausto N, Jakoby W, Schachter D, Shafritz DA, eds. The liver: biology and Pathobiology. 4th ed. Philadelphia, PA: Lippincott Williams \& Wilkins, 2001:421-435.

47. LeSage G, Glaser S, Alpini G. Regulation of cholangiocyte proliferation. Liver 2001;21:73-80.

48. Matsunaga Y, Terada T. Peribiliary capillary plexus around interlobular bile ducts in various chronic liver diseases: an immunohistochemical and morphometric study. Pathol Int 1999;49:869-873.

49. Beaussier M, Wendum D, Fouassier L, Rey C, Barbu V, Lasnier E, Lienhart A, Scoazec JY, Rosmorduc O, Housset C. Adaptative bile duct proliferative response in experimental bile duct ischemia. J Hepatol 2005;42:257-265.

50. LeCouter J, Moritz DR, Li B, Phillips GL, Liang XH, Gerber HP, Hillan KJ, Ferrara N. Angiogenesis-independent endothelial protection of liver: role of VEGFR-1. Science 2003;299:890-893.

51. Nichols MT, Gidey E, Matzakos T, Dahl R, Stiegmann G, Shah RJ, Grantham JJ, Fitz JG, Doctor RB. Secretion of cytokines and growth factors into autosomal dominant polycystic kidney disease liver cyst fluid. Hepatology 2004;40:836-846.

52. Taniguchi E, Sakisaka S, Mattsuo K, Tanikawa K, Sata M. Expression and role of vascular endothelial growth factor in liver regeneration after partial hepatectomy in rats. J Histochem Cytochem 2001;49:121-129.

53. Zachary I, Gliki G. Signaling transduction mechanisms mediating biological actions of the vascular endothelial growth factor family. Cardiovasc Res 2001;49:568-581.

54. Takahashi T, Yamaguchi S, Chida K, Shibuya M. A single autophosphorylation site on KDR/FIk-1 is essential for VEGF-A-dependent activation of PLC-gamma and DNA synthesis in vascular endothelial cells. EMBO J 2001;20:2768-2778.

55. McLaughlin AP, De Vries GW. Role of PLCgamma and $\mathrm{Ca}\left({ }^{2+}\right)$ in VEGF- and FGF-induced choroidal endothelial cell proliferation. Am J Physiol 2001;28:C1448-C1456.
56. Spyridopoulos I, Luedemann C, Chen D, Kearney M, Chen D, Murohara T, Principe N, Isner JM, Losordo DW. Divergence of angiogenic and vascular permeability signaling by VEGF: inhibition of protein kinase $C$ suppresses VEGF-induced angiogenesis, but promotes VEGF-induced, NO-dependent vascular permeability. Arterioscler Thromb Vasc Biol 2002;22:901-916.

57. Alpini G, Kanno N, Phinizy JL, Glaser S, Francis H, Taffetani S, LeSage G. Tauroursodeoxycholate inhibits human cholangiocarcinoma growth via $\mathrm{Ca}^{2+}$-, PKC-, and MAPK-dependent pathways. Am J Physiol Gastrointest Liver Physiol 2004;286:G973-G982.

58. LeSage G, Alvaro D, Glaser S, Francis H, Marucci L, Roskams T, Phinizy JL, Marzioni M, Benedetti A, Taffetani S, Barbaro B, Fava G, Ueno Y, Alpini G. Alpha-1 adrenergic receptor agonists modulate ductal secretion of $\mathrm{BDL}$ rats via $\mathrm{Ca}\left({ }^{2+}\right)$ - and $\mathrm{PKC}$-dependent stimulation of cAMP. Hepatology 2004;40:1116-1127.

59. Alvaro D, Alpini G, Onori P, Perego L, Svegliata Baroni G, Franchitto A, Baiocchi L, Glaser S, LeSage G, Folli F, Gaudio E. Estrogens stimulate proliferation of intrahepatic biliary epithelium in rats. Gastroenterology 2000;119:1681-1691.

60. Takei H, Lee ES, Jordan VC. In vitro regulation of vascular endothelial growth factor by estrogens and antiestrogens in estrogenreceptor positive breast cancer. Breast Cancer 2002;9:39-42.

61. Sengupta K, Banerjee S, Saxena N, Banerjee SK. Estradiol-induced vascular endothelial growth factor-A expression in breast tumor cells is biphasic and regulated by estrogen receptor-alpha dependent pathway. Int J Oncol 2003;22:609-614.

62. Chou MT, Wang J, Fujita VJ. Src kinase becomes preferentially associated with the VEGFR, KDR/FIk-1, following VEGF stimulation of vascular endothelial cells. BMC Biochem 2002;31:32.

Received November 3, 2005. Accepted December 14, 2005.

Address requests for reprints to: Gianfranco Alpini, PhD, Central Texas Veterans Health Care System, Texas A\&M University System Health Science Center College of Medicine, Medical Research Building, 702 SW H. K. Dodgen Loop, Temple, Texas 76504. e-mail: galpini@tamu.edu or galpini@medicine.tamu.edu; fax: (254) 724-5944 or (254) 742-7145.

Supported by a grant award from Scott \& White Hospital and the Texas A\&M University System (to G.A.); a grant award from Scott \& White Hospital (to S.G.); a VA Merit Award, a VA Research Scholar Award, and National Institutes of Health grants DK58411 and DK062975 (to G.A.); a grant from MIUR (COFIN 2003, \#2003060498_002) (to D.A.); a grant from Cofin 2000 and ex $60 \%$ (to E.G.) and MIUR (Biomedicina, Cluster C04, progetto n.ro 5) (to E.G. and P.O.); Health and Labor Sciences Research Grants for the Research on Measures for Intractable Diseases (from the Ministry of Health, Labor and Welfare of Japan); a Grant-in Aid for Scientific Research C (16590573) from JSPS (to Y.U.); and MIUR grant 2003060137_004 to the Department of Gastroenterology, Università Politecnica delle Marche, Ancona, Italy.

E.G. and B.B. contributed equally to this study. 